\title{
MIGRAÇÃO E GLOTOCÍDIO: O OCASO DE UMA LÍNGUA GERAL
}

\author{
MIGRACIÓN Y GLOTOCIDIO: EL OCASO DE UNA LENGUA GENERAL \\ IMMIGRATION AND GLOTOCIDE: THE SUNSET OF A GENERAL LANGUAGE
}

\author{
Wagner Argolo* \\ Universidade Federal da Bahia - UFBA/ PPGLinC \\ União Metropolitana de Educação e Cultura - UNIME
}

\begin{abstract}
RESUMO: Neste artigo, tratamos sobre a história externa da língua geral do sul da Bahia, levantando a hipótese de como teria se dado o seu desaparecimento: com o início da prosperidade da lavoura cacaueira - nas antigas Capitanias de Ilhéus e de Porto Seguro -, houve um forte movimento de imigração sertaneja para a região costeira em questão, causando a luta entre sertanejos (principalmente do sexo masculino, conhecidos como "jagunços") e nativos (índios, mamelucos e brancos pobres) pela posse das terras do cacau, tendo como consequência o genocídio destes últimos e o respectivo glotocídio, determinando o desaparecimento da língua geral do sul da Bahia, ao mesmo tempo em que se introduzia a língua portuguesa na região, já reformatada em sua variedade brasileira.

PALAVRAS-CHAVE: língua geral; língua portuguesa; glotocídio; mameluco; Bahia.

RESUMEN: En este artículo, tratamos sobre la historia exterior de la lengua general del sur de Bahia, apuntando la hipótesis de cómo tendría ocurrido su desaparecimiento: con el comienzo de la prosperidad en la plantación de cacao - en las antiguas Capitanias de Ilhéus y de Porto Seguro -, hubo un fuerte movimiento de inmigración del páramo para la región costera en cuestión, ocasionando la lucha entre esos inmigrantes (principalmente del sexo masculino, conocidos como "jagunços") y los nativos (indios, mamelucos y blancos pobres) por la posesión de las tierras del cacao, teniendo como consecuencia el genocidio de estos últimos y el respectivo glotocidio, determinando el desaparecimiento de la lengua general del sur de Bahia mientras se introducía la lengua portuguesa en la región, ya reconfigurada en su variedad brasileña.

PALABRAS-CLAVE: lengua general; lengua portuguesa; glotocidio; mameluco; Bahia.
\end{abstract}

ABSTRACT: In this paper, we focus on the external history of South of Bahia's general language, presenting the hypothesis on how its disappearance would have occurred: with the beginning of the prosperity of cocoa plantation - in the old Captainships of Ilheus and Porto Seguro -, there was a strong inlander immigration movement towards the region that we are treating about, causing the conflict between inlanders (mainly males, known as "jagunços") and natives (Indians, Mamelukes and impoverished Whites) who struggled for the cocoa lands' ownership, having as consequence the genocide of these last ones and the respective glotocide, determining the disappearance of South of Bahia's general language, while Portuguese language was introduced in the region, already re-structured in its Brazilian variety.

KEYWORDS: general language; Portuguese language; glotocide; Mameluke; Bahia.

\section{INTRODUÇÃO}

Em trabalho anterior (2011a, p. 99-109), procuramos demonstrar que a costa sul da Bahia - antigas Capitanias de Ilhéus e de Porto Seguro - apresentou condições sociolinguísticas para que, nessa região, se formasse uma língua geral, assim como aconteceu em São Vicente, no caso da língua geral de São Paulo (RODRIGUES, 1986, 1996, 2006). Para tanto, expusemos documentos, oriundos de fontes primárias, que atestam a existência da língua geral do Sul da Bahia, tendo sido o primeiro deles exposto ainda antes, no artigo Indícios de língua geral no sul da Bahia na segunda metade do século XVIII - de Tânia Lobo, Rosa Virgínia Mattos e Silva e Américo Machado Filho (2006, p. 609-630) -, e os demais, posteriormente, expostos no nosso referido trabalho de 2011a (ver também 2009 e 2012).

Pelo fato de ser um tema já abordado, o nosso foco, aqui, se deslocará dos questionamentos relativos à formação da língua geral na região central da costa brasileira, para o questionamento, levantado neste trabalho, de como se deu o desaparecimento de tal língua, utilizando como hipótese para a compreensão desse fato os efeitos deletérios, em termos linguísticos, causados na região pela ascensão da lavoura cacaueira, que teria, por um lado, gerado o processo imigratório inicial de sertanejos para o sul da Bahia causando a morte dos mamelucos, índios e brancos pobres, falantes de língua geral, em meio à disputa pela

\footnotetext{
* Email: wagner.argolo@gmail.com.
} 
posse das terras do cacau - e, por outro, introduzido o já "reformatado" Português Brasileiro (PB) (MATTOS E SILVA, 2004), na sua variedade popular, por ser a língua materna de tais imigrantes (cf. RIBEIRO, 2004, sobre o fato de os sertanejos brasileiros, na segunda metade do século XVIII, já serem falantes nativos do português).

Em um momento posterior à chegada dos sertanejos, quando as terras do cacau já estavam dominadas, iniciou-se mais um processo imigratório, porém de falantes do PB de outras regiões do Brasil, vindos pelo mar, a exemplo de exportadores de cacau, médicos, engenheiros e prostitutas - também falantes do PB, porém nas variedades popular e culta, e não mais apenas na popular -, consumando-se, assim, o desaparecimento da língua geral do Sul da Bahia.

Entretanto, antes de partirmos diretamente para o desenvolvimento de nossa hipótese, veremos outras duas: a primeira, referente ao declínio e desaparecimento da língua geral de São Paulo; a segunda, relativa ao declínio da língua geral da Amazônia. Note-se que, no caso desta última, utilizamos apenas o termo "declínio", pois a língua geral da Amazônia não desapareceu. Pelo contrário, continua sendo falada no Alto Rio Negro, principalmente na cidade de São Gabriel da Cachoeira-AM, onde foi co-oficializada, junto com o tukano, o baniwa e o português, em 2003, como se verá adiante.

\section{A ASCENSÃo DA LAVOURA CACAUEIRA E A QUEDA DA LINGUA GERAL DO SUL DA BAHIA}

\footnotetext{
Uma nova vida começara com o aparecimento do cacau, o que acontecera antes não contava. Engenhos e alambiques, plantações de cana e de café, legendas e histórias, tudo havia desaparecido para sempre, cresciam agora as roças de cacau e as novas legendas e histórias narrando como os homens lutaram entre si pela posse da terra. Os cegos cantadores levavam pelas feiras, até o mais distante sertão, os nomes e os feitos dos homens do cacau, a fama daquela região. (AMADO, 1989, p. 26).
}

2.1 A história linguística do Estado do Brasil e do Estado do Grão-Pará e Maranhão é fortemente marcada por genocídios e glotocídios - seja enquanto eram Estados independentes, seja depois da integração da região amazônica ao Estado do Brasil em agosto de 1823 -, tendo como resultado final, quase sempre embora por diferentes caminhos e por diferentes espaços de tempo -, o predomínio da língua portuguesa.

No que concerne às línguas gerais brasileiras, temos exemplos de seu desaparecimento ou declínio, já devidamente estudados, nos dois contextos linguísticos em que se desenvolveram: [1] o contexto sem interrupção de transmissão linguística entre gerações - no caso da língua geral de São Paulo - e [2] o contexto com interrupção de transmissão linguística entre gerações - no caso da língua geral da Amazônia (cf. ARGOLO, 2011b, p. 93-217).

2.1.1 Com relação ao contexto [1], temos o episódio da Guerra dos Emboabas, estudado por Lorenzo Vitral no seu artigo Língua geral versus língua portuguesa: a influência do "processo civilizatório" (2001, p. 303-315), no qual considera ter sido o conflito pela posse das riquezas de Minas Gerais, ocorrido em 1709 entre os bandeirantes - mamelucos falantes da língua geral de São Paulo - e os portugueses - chamados pelos bandeirantes de emboabas -, o motivo principal da frenagem da expansão da língua geral que era, então, falada também na região de Minas Gerais, colonizada inicialmente pelos bandeirantes. Isto porque os portugueses venceram a Guerra dos Emboabas, possibilitando, assim, a implantação de uma ordem institucional, por parte da Coroa de Portugal, na Capitania de Minas Gerais.

Desfechando um golpe profundo sobre a língua geral de São Paulo já com a morte de milhares de mamelucos paulistas, que sucumbiram durante a Guerra dos Emboabas, a implantação da ordem institucional se constituiu em outro golpe, também profundo, que viria a contribuir para a decadência e desaparecimento dessa língua, pois implantar a referida ordem se traduzia, em termos linguísticos, em implantar o uso da língua portuguesa. Como Minas Gerais - devido à grande riqueza que veio a obter com a extração de ouro e pedras preciosas - se tornou a capitania de maior prestígio e importância da Colônia, o seu modus vivendi passou a atuar como modelo de civilidade para as demais regiões do Estado do Brasil, principalmente para as regiões vizinhas a Minas Gerais e que eram igualmente falantes da língua geral de São Paulo, como o sul de Goiás, o Mato Grosso do Sul, o norte do Paraná e, evidentemente, a própria São Paulo, berço da referida língua geral. Assim, devido à influência do "processo civilizatório" desencadeado nas terras mineiras - cujos 
padrões de civilidade incluíam o uso da língua portuguesa -, a língua geral de São Paulo foi, paulatinamente, sendo abandonada pelos seus falantes, em benefício do idioma português:

[...] a vitória dos emboabas [portugueses], ao permitir o estabelecimento da ordem institucional na região das Minas, que veio a se tornar, no transcorrer do século XVIII, a capitania mais importante da colônia, cerceou a expansão da língua geral do sul [língua geral de São Paulo] no Brasil. Assim, a dominação política daqueles que não falavam a língua da terra foi, provavelmente, decisiva na atribuição de prestígio ao idioma lusitano. (VITRAL, 2001, p. 312).

Comparando essa afirmação de Lorenzo Vitral com o estudo de Sérgio Buarque de Holanda sobre a língua geral de São Paulo - constante no seu livro Raízes do Brasil (2002 [1936]) -, notamos que não há conflito de informações. Pelo contrário, as palavras de Sérgio Buarque de Holanda vêm confirmar a inferência de Lorenzo Vitral, quando diz que "o processo de integração efetiva da gente paulista no mundo da língua portuguesa pode dizer-se que ocorreu, com todas as probabilidades, durante a primeira metade do século XVIII" (BUARQUE DE HOLANDA, 2002, p. 1035).

2.1.2 Com relação ao contexto [Q], temos como exemplo a Revolta da Cabanagem, ocorrida entre 1835 e 1840, na agora província de Belém - pois o Estado do Grão-Pará e Maranhão já havia sido dissolvido e incorporado ao Estado do Brasil, anos antes, em 1823 -, estudada por José Ribamar Bessa Freire no seu livro Rio Babel (2004).

De cunho separatista, essa revolta causou o extermínio de um grande contingente de índios e mestiços, falantes da língua geral da Amazônia. Devido ao vazio populacional causado pela revolta e, em contrapartida, à necessidade de mão de obra surgida por causa da elevação do preço da borracha no mercado internacional, os donos dos seringais da província de Belém se viram na contingência de ter de importar uma quantidade considerável de nordestinos, falantes da língua portuguesa, para que servissem de mão de obra na extração do látex de suas árvores seringueiras.

Outrossim, houve, nesse sentido, o incentivo do governo provincial, que promoveu a imigração de estrangeiros, muitos deles portugueses, para a região, imigração esta facilitada pela grande quantidade de portos da região amazônica.

Assim, com o genocídio dos índios e mestiços da província de Belém, o glotocídio dele resultante e a maior viabilidade social que a língua portuguesa adquiriu - fazendo com que muitos dos sobreviventes da Revolta da Cabanagem, e principalmente seus descendentes, começassem a abandonar a língua geral em prol do português -, a língua geral da Amazônia perdeu grande espaço para a língua portuguesa, que, desde então, manteve o seu processo de expansão na região:

\begin{abstract}
Embora não seja possível quantificar, sabemos com segurança que, durante esse período [de 1820 a 1840], aumentou extraordinariamente o número de falantes de português e diminuiu os de LGA [língua geral da Amazônia], num processo em que o crescimento populacional não foi apenas vegetativo. Por um lado, muitos falantes de LGA foram exterminados durante a revolta popular da Cabanagem (1835-1840), enquanto os sobreviventes se retiraram para vilas e povoados; por outro, o governo provincial, através de uma caixa especial do Tesouro Público, passou a promover a introdução de colonos facilitando a imigração de estrangeiros - entre os quais portugueses - e de nordestinos, o que foi facilitado nas décadas seguintes pela navegação a vapor e pela crescente demanda internacional da borracha $[\ldots]$. Em 1868, quase $12 \%$ da população de Belém tinha a nacionalidade portuguesa [...] (FREIRE, 2003, p. 191).
\end{abstract}

Contudo, a língua geral da Amazônia é falada até hoje - embora sob outra denominação, nheengatu (que significa "língua boa") -, principalmente no Município de São Gabriel da Cachoeira-AM, no Alto Rio Negro, extremo noroeste do Brasil, onde, desde 2003, por iniciativa da Câmara de Vereadores da cidade e com o auxílio do Instituto de Investigação e Desenvolvimento em Política Linguística (IPOL), foi decretada língua oficial, junto com o tukano e o baniwa, possuindo São Gabriel da Cachoeira, hoje, quatro línguas oficiais: o nheengatu, o tukano, o baniwa e o português.

Da mesma forma que, nos exemplos dados anteriormente, relativos aos dois contextos linguísticos distintos de língua geral, o genocídio, o consequente glotocídio e o português como sendo a língua representante da civilização - e, por isso, mais viável socialmente - foram determinantes para o desaparecimento da língua geral de São Paulo e pela drástica redução do espaço de atuação da língua geral da Amazônia, assim também aconteceu com a língua geral do Sul da Bahia, que está inclusa no contexto [1]. 


\subsection{O ocaso de uma língua}

Durante a leitura dos documentos que utilizamos para obtermos o perfil sociolinguístico das duas capitanias do sul da Bahia, apenas em um único - e uma única vez - foi feita menção ao plantio de cacau, ainda assim em meio a outras colheitas, como a de mandioca, de café, de algodão e de cana, sendo o cacau apenas mais uma entre outras. Nesse documento, Luís dos Santos Vilhena, seu autor, se refere à Vila Verde, na Capitania de Porto Seguro - mais especificamente à fazenda Traípe, de propriedade dos monges beneditinos, localizada às margens do rio Mujiquiçaba, uma légua acima de Vila Verde -, não assinalando a produção de cacau nas demais vilas e aldeias, tanto da Capitania de Porto Seguro, quanto da Capitania de Ilhéus:

Subindo pelo rio na distância de três quartos de légua acima desta vila pela margem Norte do mesmo rio, se acha uma fazenda dos monges beneditinos, chamada Traípe com sua capela de pedra e cal, e existe nela um religioso fazendeiro com 11 escravos, que presentemente lavram nelas mandiocas, café, cacau, algodão, legumes, e algumas canas, cujas produções são conduzidas para a vila de Pôrto Seguro. (VILHENA, 1969 [1798-1799], p. 522, grifo nosso).

Na ocasião em que Luís dos Santos Vilhena escreveu suas cartas - entre 1798 e 1799 -, o cacau possuía pouca importância no cenário colonial, certamente porque a sua introdução em solo baiano ainda era muito recente, datada de 1746, pouco mais de 50 anos antes, quando o suíço Frédéric Louis Warneaux trouxe a primeira muda do Estado do Grão-Pará e Maranhão, plantando-a na fazenda Cubículo, situada à margem direita do rio Pardo, na Capitania de Ilhéus, onde hoje se encontra a cidade de Canavieiras (TAVARES, 2008, p. 365; SANTOS, 1957, p. 44).

Contudo, a visita de Luís dos Santos Vilhena à Capitania de Ilhéus não deve ter sido das mais morosas, pois, de acordo com a informação de Milton Santos (1957, p. 44-45), em 1783, a lavoura cacaueira já começava a dar sinais de progresso na capitania, com mais de 400.000 pés plantados, demonstrando que, pelo menos em termos locais, o cacau já começava a ganhar importância. O professor de grego, entretanto, sequer aborda a existência de pés de cacau em toda a Capitania de Ilhéus, apenas mencionando um plantio tímido em Vila Verde, na Capitania de Porto Seguro, como já foi mencionado.

Milton Santos também transcreve o trecho de um relatório escrito pelos administradores provisórios da Bahia no mesmo ano de 1783 , a respeito dos tais 400.000 pés de cacau e do progresso que a região sul da Bahia começava a experimentar: "Nos dois anos que se seguiram a estas ordens [...], mudou muito o estado da comarca”, referindo-se à Capitania de Ilhéus, e é o próprio Milton Santos quem completa, afirmando que "Daí para cá a produção do cacau só fez aumentar [...]” (1957, p. 45).

Dessa maneira, de acordo com os depoimentos expostos logo acima, podemos concluir que, de 1746 quando chegou o primeiro pé de cacau à Capitania de Ilhéus -, até o fim da década de 1770, a lavoura cacaueira não logrou grandes progressos. Somente a partir do início da década de 1780, como mostram as palavras dos administradores provisórios da Bahia, a lavoura do cacau inicia o seu processo de ascensão.

Tomando, então, o início da década de 1780 como marco que delimita o começo do progresso econômico da região, tendo como um de seus principais esteios a lavoura cacaueira, consideraremos também essa data como a que marca o início do processo de imigração dos sertanejos - seja do interior da Bahia, seja de outros estados do nordeste, principalmente de Sergipe - para o sul da Bahia.

Esses sertanejos foram afugentados de suas terras pela seca, ao mesmo tempo em que foram atraídos para o sul da Bahia pelas notícias de prosperidade da lavoura do cacau e, principalmente, pela existência de grandes extensões de terra sem dono, à espera de alguém que lá chegasse para desbravá-las e plantar os pés dos quais brotavam frutos dourados como ouro.

Dessa maneira, nas décadas seguintes, imigrantes sertanejos das mais variadas procedências - e todos falantes da língua portuguesa - partiram para as Capitanias de Ilhéus e de Porto Seguro, em lombos de burro e até mesmo de pés no chão, na esperança de garantirem o seu quinhão das terras férteis daquela região.

Contudo, as terras “sem dono”, na verdade, os tinham; donos estes que, em sua grande maioria, eram índios tupinambás, brancos pobres e mamelucos - quase todos, por sua vez, falantes da língua geral. 
Os sertanejos, ao chegarem ao sul da Bahia e ao se depararem com os nativos do lugar, partiram para cima de suas terras, tendo como consequência o conflito entre nativos e sertanejos. Estes - jagunços que se tornaram célebres pela boa pontaria nos livros de Jorge Amadon (1963, 1970, 1989) - desencadearam o processo de dizimação e expulsão dos índios tupinambás, mamelucos e brancos pobres que ocupavam as terras tornadas alvo de sua cobiça. Milton Santos, mais uma vez, nos serve de fonte, baseado agora em um estudo, na ocasião ainda um manuscrito inédito, de autoria de João Batista Alves de Macedo, do qual utiliza a seguinte citação:

A grandeza econômica da zona cacaueira foi, em boa parte, forjada pelo sertanejo e pelo nordestino, vindos do interior da Bahia e de outros Estados, especialmente Sergipe, donde a inclemência da seca os tangia em busca de melhor acolhida em terras mais férteis e dóceis, como as da zona sul da Bahia [...] (MACEDO, s/d apud SANTOS, 1957, p. 45).

E continua fazendo uso das palavras de João Batista Alves de Macedo, quando este diz que

Os jagunços, apesar de proscritos pela justiça e assalariados por aventureiros, sequiosos de fortuna fácil, foram, também, responsáveis pelo desbravamento das matas do cacau, exterminando os indígenas que, desde os primeiros séculos, constituíram um entrave à penetração do povoamento e aproveitamento dos inesgotáveis recursos econômicos da ubérrima região (MACEDO, s/d apud SANTOS, 1957, p. 45).

Esse processo de extermínio e expulsão dos índios foi, provavelmente, o principal motivo da extinção da língua geral do sul da Bahia, pois, com a morte de grande parte de seu povo e a expulsão dos seus falantes que fugiram para as matas virgens que restaram -, a lingua geral falada por eles sofreu um forte e profundo golpe.

Desse modo, ao dizimarem e expulsarem de suas terras a população autóctone falante da língua geral, os sertanejos se tornaram os principais agentes da extinção dessa língua no sul da Bahia ${ }^{1}$.

Com relação à generalização, nas Capitanias de Ilhéus e de Porto Seguro, do uso da língua portuguesa, há um fator que consideramos o mais significativo na difusão do português na costa sul baiana, à símile do que José Ribamar Bessa Freire apontou para a difusão do idioma lusitano na Amazônia: sendo estes "novos donos da terra" falantes da língua portuguesa, foi esse idioma que passou a representar a sociedade que começava a se formar: a sociedade do cacau, representada pelas primeiras gerações de imigrantes sertanejos, predominantemente do sexo masculino, que se dirigiram para o sul da Bahia, e que, passados 80 anos, já em 1860, se tornaram os primeiros grandes coronéis do cacau, assim considerados devido às grandes fortunas que acumularam e aos títulos de coronel que compraram, beneficiados que foram com a valorização do cacau no mercado internacional, como resultado da grande procura por esse produto pelas indústrias norteamericanas do ramo farmacêutico e alimentício, além da procura por parte de países europeus, como a Inglaterra, que também se interessaram pelo produto (TAVARES, 2008, p. 365).

Além do mais, a própria localização geográfica da Zona do Cacau favorecia a imigração. Por terra, chegaram os primeiros imigrantes sertanejos - responsáveis, por um lado, pela dizimação e expulsão dos tupinambás, mamelucos e brancos pobres, resultando na morte de sua língua geral e, por outro, pela introdução da língua portuguesa na região -, que, do interior nordestino, partiram para a costa sul da Bahia. Pelo mar - após o estabelecimento dos imigrantes sertanejos, quando as terras do sul da Bahia já estavam repletas de fazendas de cacau e o dinheiro começava a circular em abundância na região -, começaram a aportar, principalmente

\footnotetext{
${ }^{1}$ Mas não podemos atribuir a extinção da língua geral do sul da Bahia apenas à imigração dos sertanejos para essa região, pois, como constatamos na documentação utilizada no perfil das vilas e aldeias das Capitanias de Ilhéus e de Porto Seguro, desde 1758, as Reformas Pombalinas começaram a atuar na região. É verdade, como percebemos no caso da Vila de Olivença - na Capitania de Ilhéus - em 1794, que, em termos linguísticos, o Diretório dos Índios ainda não havia surtido o efeito esperado, pois, nesse ano, a língua geral continuava sendo falada por grande parte de sua população, muito provavelmente, como L1, assim como na Vila do Prado - na Capitania de Porto Seguro -, em 1804, na qual sua população também continuava a falar a língua geral, nesse caso com certeza, como L1. Contudo, se na Vila de Olivença em 1794, por um lado, a língua geral ainda era o idioma corrente de sua população, dando um atestado da ineficiência das medidas pombalinas, por outro lado, nesse mesmo ano, podemos observar uma reação da Coroa Portuguesa no sentido reverter essa situação, indicando Manuel do Carmo de Jesus para ser o novo Diretor de Índios do lugar, fato que parece ter surtido efeito, pois, anos depois, já não se encontravam mais, pelo menos às vistas e ouvidos do Ouvidor Maciel, pessoas falando língua geral publicamente, mas a língua portuguesa. Dessa maneira, se medidas desse tipo foram tomadas com relação à Vila de Olivença, possivelmente foram tomadas, também, com relação às demais vilas da Capitania de Ilhéus, o mesmo valendo para as vilas da Capitania de Porto Seguro, pois situação semelhante de uso da língua geral foi constatada na Vila do Prado em 1804, como já foi dito, o que nos leva a crer que, se o Diretório dos Índios não foi o principal fator que determinou a extinção da língua geral do sul da Bahia e a ascensão da língua portuguesa nessa região, foi, contudo, um fator importante.
} 
em Ilhéus, imigrantes de outras regiões do país, a exemplo do sudeste, cujas profissões eram as mais diversas - como médicos, engenheiros, prostitutas e exportadores de cacau.

2.2.1 Dados demográficos do século XX, mais especificamente de 1940, relativos à Zona do Cacau, reforçam a hipótese que estamos expondo neste artigo, ou seja, a de que um processo de imigração significativo de sertanejos (principalmente os do sexo masculino, que vieram a ser traduzidos na figura do "jagunço", responsáveis, em grande parte, pelo extermínio da população autóctone da região) teria sido o responsável pela dizimação dos falantes da língua geral do Sul da Bahia - resultando na extinção de sua língua -, ao mesmo tempo em que introduziu o PB como nova língua predominante na região.

Referimo-nos ao Ensaio de descrição estatística de uma zona fisiográfica (Zona Cacaueira do Estado da Bahia) pelos dados do recenseamento - publicado em 1952, pelo Instituto Brasileiro de Geografia e Estatística (IBGE), e escrito por Giorgio Mortara -, no qual são encontrados dados demográficos relevantes sobre a população do sul da Bahia em 1940, quando a economia baseada no plantio do cacau já estava consolidada, assim como sua população (cujo processo de formação se iniciou com os primeiros imigrantes de 1780), que, como foi visto acima, era composta principalmente por imigrantes sertanejos, tanto do Estado da Bahia, como de outros estados.

Como se verá, enquanto, no período anterior ao desenvolvimento da lavoura cacaueira, a população de todo o sul da Bahia não passava de pouco mais de 20.000 pessoas (ARGOLO, 2011b) - entre índios, mamelucos e brancos pobres -, a partir do incremento da lavoura cacaueira, em 1780, a imigração de sertanejos foi responsável por um espantoso crescimento demográfico na região, atingindo um número superior a 460.000 pessoas, como mostram os dados do censo do IBGE estudados por Giorgio Mortara. O censo em questão foi feito 160 anos após o início de tal processo imigratório, confirmando, portanto, as inferências que viemos expondo neste trabalho:

Tabela 1 - Zona cacaueira - população em 1940, por Municípios

\begin{tabular}{|c|c|}
\hline MUNICÍPIO & $\begin{array}{c}\text { POPULAÇÃO } \\
\text { hab. }\end{array}$ \\
\hline & 1940 \\
\hline 1. Belmonte & 27.580 \\
\hline 2. Cairu & 4.948 \\
\hline 3. Camamu & 22.312 \\
\hline 4. Canavieiras & 36.064 \\
\hline 5. Ilhéus & 113.269 \\
\hline 6. Ipiaú & 33.653 \\
\hline 7. Itabuna & 96.879 \\
\hline 8. Itacaré & 22.701 \\
\hline 9. Ituberá & 21.012 \\
\hline 10. Maraú & 11.205 \\
\hline 11. Nilo Peçanha & 12.508 \\
\hline 12. Taperoá & 8.995 \\
\hline 13. Ubaitaba & 12.141 \\
\hline 14. Una & 9.287 \\
\hline 15. Valença & 29.442 \\
\hline ZONA CACAUEIRA & 461.996 \\
\hline
\end{tabular}

No referido ensaio, Giorgio Mortara afirma que a importância demográfica da Zona do Cacau era maior do que a sua importância territorial, pois, segundo dados do IBGE de $1^{\circ}$ de setembro de 1940, a população da zona correspondia a um oitavo da população de todo o Estado da Bahia - com 461.996 habitantes (cf. Tabela 1), sendo $52,54 \%$ de homens e $47,45 \%$ de mulheres -, enquanto a extensão do seu território - perfazendo uma área total de $27.403 \mathrm{Km}^{2}$ - correspondia a, apenas, um vigésimo do território de todo o estado:

A Zona Cacaueira abrange uma área de 27403 quilômetros quadrados, que corresponde a menos de um vigésimo da área total do Estado da Bahia. 
Entretanto a sua população, que em primeiro de setembro de 1940 excedia 460 ooo habitantes [...], constitui cerca de um oitavo da população total do Estado.

A importância demográfica da zona é, portanto, bem superior à sua importância territorial (MORTARA, 1952, p. 11).

Desse número de 461.996 habitantes, os que são considerados especialmente aptos para o trabalho estão entre as idades de 20 e 59 anos - incluindo homens e mulheres -, o que representa 44,55\% da população total. Desses $44,55 \%$ especialmente aptos, $24,47 \%$ são homens e $20,08 \%$ são mulheres. É justamente dentro dessa faixa etária que está a maior proporção de homens em relação a mulheres: "Localiza-se, portanto, principalmente nas idades mais válidas o excedente masculino, característico da população da zona" (MORTARA, 1952, p. 22).

Comparando-se a percentagem de 44,55\% de ativos (incluindo homens e mulheres) com o percentual análogo da Bahia como um todo, vemos que a Zona do Cacau apresentava, em 1940, um maior contingente populacional em idade ativa, dentro da faixa etária de 20 a 59 anos, pois, para o conjunto da Bahia, temos um percentual de ativos (incluindo homens e mulheres) de $41,92 \%$, dividido em 20,13\% de homens e $21,79 \%$ de mulheres. Nesse ponto, não se pode deixar de assinalar o fato de que, dentro da população ativa do conjunto da Bahia, o percentual de mulheres ativas (21,79\%) é maior do que o de homens (20,13\%), diferentemente do que ocorria na Zona do Cacau, na qual o percentual de homens ativos $(24,47 \%)$ era maior do que o de mulheres (20,08\%), situação que resulta, no caso específico da Zona do Cacau, do caráter predominantemente masculino de sua imigração, como se verá a seguir.

O maior percentual de homens em atividade, na faixa entre 20 e 59 anos, se explica pela essência agrícola da economia cacaueira, que exigia uma quantidade maior de mão de obra masculina para o trabalho pesado em meio às roças de cacau. Tal caráter predominantemente masculino da imigração sertaneja para o sul da Bahia não pode passar despercebido. Pelo contrário, deve ser ressaltado, devido à importância que assume ao corroborar as informações apresentadas por Milton Santos e Luís Henrique Dias Tavares, quando afirmam que foi o sertanejo - que muitas vezes já atuava como jagunço para outros coronéis nos interiores pastoris do mesmo "Brasil Crioulo" (cf. RIBEIRO, 2004, p. 274-306) - o responsável pelo desbravamento das matas do cacau, cuja frente de expansão teria conduzido ao conflito com os povos autóctones, resultando no seu genocídio e, como estamos a afirmar, no consequente glotocídio de sua língua geral.

Já o menor percentual de mulheres em atividade, na mesma faixa etária, se deve à utilização de sua mão de obra em serviços domésticos, que, embora oferecessem muitas oportunidades de trabalho, não faziam frente à demanda, cada vez maior, de mão de obra exigida pelas fazendas de cacau, porque esta era a principal atividade econômica da zona:

O excedente masculino da população na Zona Cacaueira depende principal e talvez exclusivamente da imigração de trabalhadores agrícolas, de outras partes do Estado e de outros Estados, para esta zona. Ver-se-á mais adiante que esse excedente se localiza nas idades mais válidas. [...] Os homens de 20 a 59 anos constituem quase um quarto desta população, enquanto no conjunto do Estado a proporção correspondente excede de pouco um quinto. [...] A predominância masculina verifica-se em 13 dos 15 Municípios, variando nestes a proporção dos homens para 1000 mulheres entre o máximo de 1213 (Una) e o mínimo de 1005 (Ipiaú) [...] (MORTARA, 1952, p. 20-22).

Vejamos, agora, dados demográficos da população da Zona do Cacau como um todo, sem especificação por município, constantes no Ensaio de descrição estatística de uma zona fisiográfica (Zona Cacaueira do Estado da Bahia) pelos dados do recenseamento, distribuídos por sexo e idade, incluindo, agora, todas as faixas etárias utilizadas no recenseamento em questão, relativo ao ano de 1940.

Assim, de 0 a 9 anos, há um excedente masculino de 4,2\%, como um simples resultado do maior crescimento vegetativo nesse sexo; de 10 a 19 anos, de acordo com os dados colhidos, há um grande equilíbrio entre o número de homens e mulheres (Giorgio Mortara, no entanto, considera que o equilíbrio nessa faixa etária não corresponde à realidade, pois as mulheres tenderiam, segundo ele, a declarar uma idade inferior à verdadeira, o que gerou uma "inflação" nessa faixa etária feminina); de 20 a 29 anos, há um excedente masculino de 12,8\%; de 30 a 39 anos, há um excedente masculino de 23,7\%; de 40 a 49 anos, há um excedente masculino de $34,5 \%$; de 50 a 59 anos, há um excedente masculino de $36,3 \%$; e de 60 a 69 anos, também há um excedente masculino de $18,7 \%$. Já nas faixas etárias de 70 a 79 anos e de 80 anos em diante, a proporção se inverte, passando a prevalecer um excedente de mulheres, fato que, segundo Giorgio 
Mortara, se explica, em grande parte, pela maior taxa de mortalidade dos homens. Vejamos (atenção para a faixa etária entre 20 e 59 anos, grifada na Tabela 2, pois nela se confirma o excedente masculino cuja importância foi ressaltada há pouco):

Tabela 2 - Zona cacaueira - Distribuição da população segundo o sexo e a idade, em 1940

\begin{tabular}{|c|c|c|c|c|c|}
\hline \multirow{2}{*}{$\begin{array}{c}I D A D E \\
\text { Anos completos }\end{array}$} & \multicolumn{3}{|c|}{ POPULAÇÃO PRESENTE } & \multirow{2}{*}{$\begin{array}{c}\text { DIFE- } \\
R E N C ̧ A \\
H .-M .\end{array}$} & \multirow{2}{*}{$\begin{array}{c}\text { PRO- } \\
\text { PORÇÃO } \\
\text { H. para } \\
1000 \text { M. }\end{array}$} \\
\hline & Homens & Mulheres & $\begin{array}{l}\text { Homens e } \\
\text { Mulheres }\end{array}$ & & \\
\hline o a 9 & 69.404 & 66.596 & 136.000 & +2.808 & 1.042 \\
\hline 10 a 19 & 51.947 & 51.970 & 103.917 & -23 & 1.000 \\
\hline 20 a 29 & 47.312 & 41.935 & 89.247 & +5.377 & 1.128 \\
\hline 30 a 39 & 31.708 & 25.640 & 57.348 & +6.068 & 1.237 \\
\hline 40 a 49 & 21.690 & 16.123 & 37.813 & +5.567 & 1.345 \\
\hline 50 a 59 & 12.337 & 9.051 & 21.388 & +3.286 & 1.363 \\
\hline 60 a 69 & 5.706 & 4.809 & 10.515 & +897 & 1.187 \\
\hline 70 a 79 & 1.776 & 1.979 & 3.755 & -203 & 897 \\
\hline 80 e mais & 834 & 1.080 & 1.914 & -246 & 772 \\
\hline Ignorada & 53 & 46 & 99 & +7 & $\ldots$ \\
\hline$T O T A L$ & 242.767 & 219.229 & 461.996 & +23.538 & 1.219 \\
\hline
\end{tabular}

Na tabela seguinte, também relativa a 1940, temos a distribuição da população de 10 anos ou mais, de acordo com o sexo e com a atividade de trabalho. Nela, ao observarmos o ramo de atividade I ("Agricultura, pecuária, etc.”), percebemos uma prevalência categórica do sexo masculino, com 110.531 homens, o que representa $63,76 \%$ do universo total de homens de 10 anos ou mais. Ao observarmos o ramo de atividade XI (“Atividades domésticas e escolares"), de maneira inversa, é clara a prevalência do sexo feminino, com 121.244 mulheres, o que se traduz em $79,43 \%$ do total de mulheres de 10 anos ou mais. Como se vê, comparando-se o número de homens e de mulheres de 10 anos ou mais, tendo como base apenas os ramos de atividade I e XI, temos a falsa impressão de uma prevalência demográfica feminina, fato que logo se esclarece se forem observados os demais ramos, de II a IX e o ramo XII (com exceção apenas do ramo X), nos quais também é observada uma clara predominância masculina, fruto da diversificação de sua mão de obra entre as outras atividades, surgidas com o desenvolvimento socioeconômico da zona.

Desse modo, se considerada a população masculina de 10 anos ou mais, distribuída por todos os 12 ramos de atividade, temos um somatório final de homens maior do que o somatório final de mulheres na mesma circunstância, ou seja, 173.363 homens, contra 152.633 mulheres:

Tabela 3 - Zona cacaueira - Distribuição da população de 10 anos e mais segundo o sexo e o ramo de atividade principal, em 1940

\begin{tabular}{|c|c|c|c|c|}
\hline \multirow[t]{2}{*}{ RAMO DE ATIVIDADE } & \multicolumn{2}{|c|}{ NÚMEROS ABSOLUTOS } & \multicolumn{2}{|c|}{ PERCENTAGENS } \\
\hline & Homens & Mulheres & Homens & Mulheres \\
\hline I. Agricultura, pecuária, etc. & 110.531 & 8.082 & 63,76 & 5,29 \\
\hline II. Indústrias extrativas & 4.355 & 224 & 2,51 & 0,15 \\
\hline III. Indústrias de transformação & 10.847 & 1.525 & 6,26 & 1,00 \\
\hline IV. Comércio de mercadorias & 7.509 & 327 & 4,33 & 0,21 \\
\hline V. Comércio de valores, etc & 142 & 10 & 0,08 & 0,01 \\
\hline VI. Transportes e comunicações & 4.148 & 39 & 2,39 & 0,03 \\
\hline $\begin{array}{l}\text { VII. Administração pública, justiça e } \\
\text { ensino público }\end{array}$ & 1.279 & 317 & 0,74 & 0,21 \\
\hline $\begin{array}{l}\text { VIII. Defesa nacional e segurança } \\
\text { pública }\end{array}$ & 330 & 3 & 0,19 & 0,00 \\
\hline $\begin{array}{l}\text { IX. Profissões liberais, culto, ensino } \\
\text { particular, etc }\end{array}$ & 493 & 225 & 0,28 & 0,15 \\
\hline X. Serviços e atividades sociais & 5.945 & 6.069 & 3,43 & 3,98 \\
\hline $\begin{array}{l}\text { XI.Atividades domésticas e } \\
\text { escolares }\end{array}$ & 8.852 & 121.244 & 5,11 & 79,43 \\
\hline XII. Inativos, etc & 18.932 & 14.568 & 10,92 & 9,54 \\
\hline TOTAL & 173.363 & 152.633 & 100,00 & 100,00 \\
\hline
\end{tabular}

Fonte: Mortara (1952, p. 25, grifo nosso). 
Os dados demográficos expostos acima comprovam o espantoso crescimento populacional do sul da Bahia como resultado da prosperidade da lavoura cacaueira, assim como a predominância do sexo masculino no seio dessa população, reforçando, desse modo, a nossa hipótese de que teriam sido tais sertanejos, tornados ou mantidos como jagunços, os principais responsáveis pela dizimação da população autóctone do sul da Bahia, outrora falante de língua geral.

2.2.2 Dois exemplos muito conhecidos - que representam tanto a imigração sertaneja inicial, feita por terra, quanto a imigração posterior, de outras regiões do Brasil (o sudeste é uma delas), feita pelo mar - podem ser encontrados em um único livro de Jorge Amado, Gabriela, Cravo e Canela.

No início do século XX, com a cidade de Ilhéus estabelecida e com todas as suas terras de escritura lavrada em cartório, a personagem Gabriela é um exemplo do imigrante sertanejo que, por terra, vem do interior do nordeste para o litoral sul da Bahia, fugindo da seca. Foi assim que teve início a sua história com Nacib, que, atrás de uma cozinheira - pois a sua antiga, a velha Filomena, o havia deixado -, a encontrou no "Mercado dos Escravos", coberta de poeira da cabeça aos pés, após semanas caminhando descalça até chegar à "terra prometida", resolvendo contratá-la, após Gabriela tê-lo chamado de "moço bonito". O local onde Nacib a encontrou, situado atrás da estrada de ferro de Ilhéus, era chamado de "Mercado dos Escravos", porque para lá iam os imigrantes sertanejos pobres recém-chegados, para serem avaliados por pessoas interessadas em contratar empregadas domésticas, cozinheiras e, principalmente, trabalhadores para as roças de cacau, guardando certa semelhança com os mercados de gente do período da escravidão, cujo término ainda era recente naquele início de século XX.

Já um exemplo de imigrante do sudeste, que veio pelo mar, é o personagem Raimundo Mendes Falcão tratado por todos como Mundinho Falcão -, jovem que aportou em Ilhéus, vindo do Rio de Janeiro, para trabalhar como exportador de cacau e com a cabeça prenhe de ideias progressistas - destoando do pensamento dos coronéis desbravadores da terra -, acabando por se tornar o chefe político da Zona Cacaueira - depois de atentados, de incêndios de jornais oposicionistas e da morte de seu adversário principal e antigo chefe político da região, o velho coronel Ramiro Bastos, que, inclusive, era também sertanejo e integrante das primeiras gerações de coronéis que resolviam os seus conflitos a bala nas famosas tocaias.

Apesar de se tratar de um romance - o que implica na necessidade de pesar o que é ficção e o que é, de fato, história -, as informações dadas pelo historiador Luís Henrique Dias Tavares, pelo sociólogo Milton Santos e pelo Ensaio de descrição estatística de uma zona fisiográfica (Zona Cacaueira do Estado da Bahia) pelos dados do recenseamento nos permitem afirmar que, mesmo Gabriela e Raimundo Mendes Falcão tendo sido apenas personagens criados por Jorge Amado, tratam-se, ainda assim, de criações baseadas na realidade social e factual não apenas de Ilhéus, mas da Zona do Cacau como um todo.

Corroboram tal inferência as palavras do crítico literário Massaud Moisés, encontradas no seu livro $A$ criação literária (1978), quando afirma que "o romancista joga com a intuição e a imaginação, que desenvolvem e trabalham os dados colhidos da realidade banal e diária [...]” (p. 98, grifo nosso). E continua, ao dizer que

o drama das personagens há de ser universal em si, por nascer de inquietudes espirituais perenes (a condição humana, o sentido da vida, o ser e o não-ser, etc.) ou de 'situações' históricas momentaneamente universalizadas (a fome, as catástrofes, a escravidão, a opressão, etc.). (MOISÉS, 1978, p. 98).

2.3 Dessa maneira, após a dizimação e expulsão dos índios tupinambás, dos mamelucos e dos brancos pobres, falantes da língua geral, a região sul da Bahia ficou aberta para a entrada da língua portuguesa por todos os lados: pela terra e pelo mar.

Por fim, os próprios índios falantes da língua geral, que fugiram para as matas virgens - além dos cacauais -, com o passar do tempo, possivelmente se viram na contingência de restabelecer contato com a região tomada pelos sertanejos - sem mais lhes oferecer resistência, em busca de melhores condições de vida -, contato este que só era possível em língua portuguesa, tornando-se a língua mais viável socialmente, provocando, como consequência dessa viabilidade, o abandono paulatino da língua geral e a adoção da língua portuguesa também por eles. 


\section{CONCLUSÃO}

Neste artigo, expusemos as hipóteses de Lorenzo Vitral e de José Ribamar Bessa Freire, relativas à morte e ao declínio das línguas gerais de São Paulo e da Amazônia, respectivamente, para, em seguida, baseados nos autores citados, lançarmos nossa própria hipótese sobre a morte da língua geral do Sul da Bahia.

Portanto, sobre essa questão, consideramos que o processo de imigração sertaneja para esta região, a partir da década de 1780 - e que teve como uma de suas principais características a luta sangrenta pela posse das terras férteis e propícias ao cultivo do cacau -, foi o principal motivo do declínio e desaparecimento de sua língua geral, pois os seus falantes ou morreram nos conflitos pela posse da terra, ou fugiram para as matas virgens onde a frente de expansão cacaueira ainda não havia chegado.

Desse modo, os sertanejos das mais variadas procedências, principalmente do estado de Sergipe, depois de se tornarem os novos donos da terra e de desbravarem as abundantes matas virgens da região, teriam sido os responsáveis por plantar, junto com os pés de cacau, a língua portuguesa naquele solo que, durante os 200 anos seguintes, se tornaria um dos mais valiosos do Brasil, até se iniciar o processo de decadência econômica da Zona do Cacau na década de 1980.

\section{REFERÊNCIAS}

AMADO, Jorge. Cacau. São Paulo: Martins Fontes, 1963.

Terras do sem fim. Martins Fontes, 1970.

Gabriela, cravo e canela. Rio de Janeiro: Nova Aguilar, 1989.

ARGOLO, Wagner. O passado linguístico indígena e as línguas gerais entre o Rio de Janeiro e o Piauí: busca por documentos no Arquivo Histórico Ultramarino entre 1758 e 1794. In: OLIVEIRA, Klebson; CUNHA E SOUZA, Hirão F.; GOMES, Luís (Orgs.). Novos tons de rosa: para Rosa Virgínia Mattos e Silva. Salvador: EDUFBA, 2009. p. 62-74.

. Língua geral na Bahia: Comarcas de Ilhéus e Porto Seguro. In: CARVALHO, Cristina dos Santos; ROCHA, Flávia Aninger de Barros; PARCERO, Lúcia Maria de Jesus (Orgs.). Discurso e cultura: diálogos interdisciplinares. Salvador: EDUNEB, 2011 a. p. 99-109.

Introdução à história das línguas gerais no Brasil: processos distintos de formação no período colonial. Dissertação (Mestrado em Linguística) - Universidade Federal da Bahia, Salvador, 2011b.

. História linguística do Sul da Bahia: levantando hipóteses e iluminando caminhos. Entrepalavras, Fortaleza, v. 2, n. 1, p. 270-292, 2012.

BUARQUE DE HOLANDA, Sérgio. Raizes do Brasil. Rio de Janeiro: Nova Aguilar, 2002.

FREIRE, José Ribamar Bessa. Língua Geral Amazônica: a história de um esquecimento. In: FREIRE, José Ribamar Bessa; ROSA, Maria Carlota (Orgs.). Linguas gerais: política lingüística e catequese na América do Sul no período colonial. Rio de Janeiro: EDUERJ, 2003. p. 195-207.

Rio Babel: a história das línguas na Amazônia. Rio de Janeiro: Atlântica, 2004.

LOBO, Tânia; MACHADO FILHO, Américo Venâncio Lopes; MATTOS E SILVA, Rosa Virgínia. Indícios de língua geral no sul da Bahia na segunda metade do século XVIII. In: LOBO et al (Orgs.). Para a história do português brasileiro. Salvador: EDUFBA, 2006. p. 609-630.

MATTOS E SILVA, Rosa Virgínia. Ensaios para uma sócio-história do português brasileiro. São Paulo: Parábola, 2004. p. 69-108.

MOISÉS, Massaud. A criação literária. São Paulo: Cultrix, 1978.

MORTARA, Giorgio. Ensaio de descrição estatística de uma zona fisiográfica (Zona Cacaueira do Estado da Bahia) pelos dados do recenseamento. Rio de Janeiro: Instituto Brasileiro de Geografia e Estatística, 1952.

RIBEIRO, Darcy. O povo brasileiro: a formação e o sentido do Brasil. São Paulo: Companhia das Letras, 2004. 
RODRIGUES, Aryon. Linguas brasileiras: para o conhecimento das línguas indígenas. São Paulo: Loyola, 1986.

. As línguas gerais sul-americanas. Brasília: UnB/ Laboratório de línguas indígenas, 1996. Disponível em: <http://www.unb.br>. Acesso em: 10 ago. 2009.

. As outras línguas da colonização do Brasil. In: CARDOSO, Suzana; MOTA, Jacyra; MATTOS E

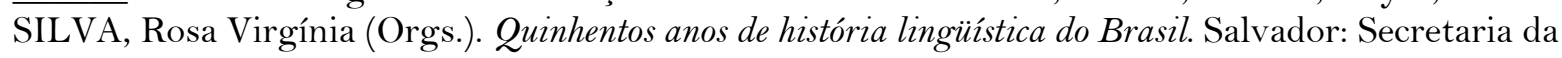
Cultura e Turismo do Estado da Bahia, 2006. p. 143-161.

SANTOS, Milton. Zona do Cacau. São Paulo: Brasiliana, 1957. p. 39-48.

TAVARES, Luís Henrique Dias. História da Bahia. Salvador: EDUFBA; São Paulo: UNESP, 2008. p. 91102; 364-366.

VILHENA, Luís dos Santos. A Bahia no século XVIII. Salvador: Editora Itapuã, 1969 [1798-1799]. p. 437514.

VITRAL, Lorenzo. Língua geral versus língua portuguesa: a influência do "processo civilizatório". In: MATTOS E SILVA, Rosa Virgínia (Org.). Para a história do português brasileiro. São Paulo: Humanitas, 2001. p. 303-315.

Recebido em 16/o2/13. Aprovado em 19/06/13. 